\title{
Estriol Measurement
}

National Cancer Institute

\section{Source}

National Cancer Institute. Estrio/ Measurement. NCI Thesaurus. Code C74856.

The determination of the amount of estriol hormone present in a sample. 